\title{
Implementation of a Community-Based Low-Calorie Dietary Intervention for the Induction of Type-2 Diabetes and Pre-Diabetes Remission: A Feasibility Study Utilising a Type-2 Hybrid Design
}

Kim Quimby ( $\nabla$ kim.quimby@cavehill.uwi.edu )

The University of the West Indies https://orcid.org/0000-0001-8056-0187

Natasha Sobers

The University of the West Indies

Colette George

The University of the West Indies

Natalie Greaves

The University of the West Indies

Francine Browman-Jones

Ministry of Health, Barbados

\section{T Alafia Samuels}

The University of the West Indies

\section{Research}

Keywords: type-2 diabetes, diabetes remission, weight loss, community intervention, community health advocates, faith-based organization, low-calorie diet, overweight

Posted Date: April 27th, 2021

DOl: https://doi.org/10.21203/rs.3.rs-447846/v1

License: (c) (i) This work is licensed under a Creative Commons Attribution 4.0 International License. Read Full License 


\section{Abstract \\ Objectives}

The aims of this feasibility study were to (1) examine the implementation of a community-based health advocate ( $\mathrm{CHA}$ ) training program to develop the clinical skills needed to support a diabetes remission protocol based on a low-calorie diet (LCD) and (2) investigate if participant weight loss can be achieved and diabetes remission induced under these conditions.

\section{Methods}

This tripartite study followed a type-2 implementation-effectiveness design. Three faith-based organizations (FBOs) were purposively selected as study sites. Implementation outcomes were guided by the Consolidated Framework for Implementation Research. During the pre-implementation phase, site 'readiness' to facilitate the intervention was determined from a site visit and an interview with the FBOs' leadership. During the implementation phase, congregants could volunteer for the 10-week CHA training which included practical exercises in weight, glucose and blood pressure (BP) measurement, and a summative practical assessment. Acceptability and implementation effectiveness were assessed via survey. During the intervention phase, other congregants and community members with T2DM or prediabetes and overweight were invited to participate in the 12-week LCD. Anti-diabetic medication was discontinued on day-1 of the intervention. Clinical effectiveness was determined from the change in weight, fasting blood glucose (FBG) and BP which were monitored weekly at the FBO by the CHA. HbA1C was performed at week 1 and 12 .

\section{Results}

The FBOs were found to be ready as determined by their adequate resources and engagement in healthrelated matters. Twenty-nine CHAs completed the training; all attained a passing grade at $\geq 1$ clinical station, indicating implementation effectiveness. CHA feedback indicated that the program structure was acceptable and provided sufficient access to intervention-related material. Thirty-one persons participated in the LCD (11 T2DM:20 pre-diabetes). Mean (95\% Cl) weight loss was $6.8 \mathrm{kgs}(5.4-8.2) \mathrm{p}<0.00001$; $7.9 \mathrm{kgs}$ in males vs $6.6 \mathrm{kgs}$ in females; A1C decreased from 6.6-6.2\%, $p=0.003$ and FBG from 6.4$6.0 \mathrm{mmol} / \mathrm{L} ; \mathrm{p}=0.004$. T2DM remission rates were $60 \%$ and $90 \%$ by $\mathrm{A} 1 \mathrm{C}<6.5 \%$ and $\mathrm{FBG}<7 \mathrm{mmol} / \mathrm{L}$ respectively. Pre-diabetes remission was $18 \%$ and $40 \%$ by $A 1 C<5.7 \%$ and $F B G<5.6$ respectively.

\section{Conclusion}

Implementation of a community-based diabetes remission protocol is both feasible and clinically effective. Its sustainability is to be determined. Adaptability to other disorders or other settings should be 


\section{Trial Registration}

: NCT03536377 registered 24th May 2018 at https://clinicaltrials.gov/ct2/show/NCT03536377

\section{Contribution To The Literature}

- Weight loss-induced T2DM remission due to a low-calorie diet is feasible in clinical settings, however, its feasibility in a community-based approach is not yet established.

- This study shows that faith-based organizations are equipped to successfully support a Community Health Advocates training program aimed at increasing the skills necessary for T2DM screening and the effective delivery of a weight loss and T2DM remission protocol; more-over weight loss and T2DM and pre-diabetes remission can be achieved under these conditions.

- We recommend community-based screening for T2DM and pre-diabetes and propose investigating the adaptability of this intervention to other community sites and disease states.

\section{Background}

The 2019 International Diabetes Federation report estimated that 463M adults are living with diabetes (1). As with other non-communicable diseases (NCDs), the prevalence is highest in high income countries, with North America and the Caribbean (NAC) bearing the highest burden. The prevalence of pre-diabetes is also increasing; and the 5-year conversion rate to type-2 diabetes mellitus (T2DM) ranges from 26$50 \%$, influenced by a complex interplay of factors such as weight, age, race and an obesogenic environment that compromises the lifestyle measures necessary for T2DM control (2-7). Likewise, obesity prevalence has nearly tripled in the last 50 years (8). Within NAC, the prevalence of obesity was $28 \%$, increasing to $62.5 \%$ when overweight data were included $(9,10)$.

Historically, T2DM has been viewed as a life-long illness, however recent interventions are shifting this perception. Weight loss, as a result of bariatric surgery and low-calorie dietary interventions (LCD), has led to the concept of 'diabetes remission' as defined by the restoration of $\beta$ cell function and insulin sensitivity and the resultant normalization of blood glucose (11-13). The Barbados Diabetes Reversal Study-1 (BDRS1), a small, clinic-based study, has confirmed that the metabolic effects achieved in a predominantly Black population are comparable with those in the predominantly White population where the protocol was originally published (14).

Although the treatment options for overweight and T2DM are increasing, disparities in access still exist (1). Empowering community health advocates ( $\mathrm{CHA})$ is a useful implementation strategy in the advancement of community-based clinical interventions, and has been shown to increase accessibility while maintaining health outcomes comparable to physician-led efforts $(15,16)$. The use of faith-based 
organisations (FBO) as community sites is particularly common in ethnic minority and underserved people groups (17)(18).

The setting

Barbados is a 166 square mile Caribbean island with a population of approximately 280,000 . Consistent with the epidemiologic profile of most small island developing states, NCDs are responsible for $>80 \%$ of deaths, and the risk of premature deaths from NCDs is approximately $16 \%$ (19). While coronary heart disease is the number one cause of death, T2DM is the primary metabolic contributor to NCD deaths on the island.

The Barbados Health of the Nation 2012 study reported that $18.7 \%$ of the population had a diagnosis of T2DM; of these $13.8 \%$ were unaware of their status and $66.7 \%$ were uncontrolled (20). An additional $14.7 \%$ of the population had impaired fasting glucose and $66 \%$ were overweight inclusive of $33 \%$ who were obese. Understandably, diabetes related complications consume a significant portion of healthcare expenditure (21). The Barbados government, in adopting a whole-of-society approach to NCDs, has engaged FBOs, who now have representation on the island's NCD commission (22). This level of civil society engagement is in alignment with the Caribbean Community (CARICOM) strategy for combatting NCDs as articulated in the Port-of-Spain declaration (23). Importantly, Barbados has a high density of FBOs, many of which are integrated into the surrounding communities, including functioning as community disaster shelters. Given this local context, FBOs may be viewed as being acceptable and accessible locations for the implementation of community-based interventions.

\section{Aim}

The overarching aim of the Barbados Diabetes Remission Study 2 (BDRS2) was to investigate the feasibility of implementing a community-based low calorie dietary intervention (LCD) for the induction of T2DM and pre-diabetes remission using a type-2 implementation-effectiveness hybrid design.

\section{Methods}

The protocol included three distinct steps: (1) the pre-implementation phase where readiness of the FBO was determined (2) the implementation phase which utilised an implementation strategy focused on increasing the knowledge and skills of CHA to support the LCD (3) the intervention phase where eligible persons participated in the LCD and were supported by the trained CHAs (Fig. 1).

\section{(1) Pre-implementation}

The process for assessing the readiness of FBOs is presented in three main steps: (i) purposive selection of FBOs (ii) determination of implementation outcomes and (iii) development and use of an assessment tool for implementation outcomes (Fig. 1). 


\section{i) Purposive selection of the FBO:}

The two main criteria for FBO selection were a medical doctor must be part of the FBO membership and be available to consult with the local study team and an attendance of $>100$ persons at the FBO's main worship service as this could provide a large enough sampling frame.

\section{ii) Definition of implementation outcomes:}

Implementation outcomes were defined as by the Consolidated Framework for Implementation Research (CFIR). These included (a) 'readiness for implementation' an inner setting construct and (b) 'knowledge and beliefs about the intervention' which encompasses individuals' attitudes towards the intervention, and (c) 'individual state of change' both of which mapped to the individual characteristics construct.

(a) Readiness encompasses three core elements (1) leadership engagement, (2) the availability of resources and (3) access to intervention-related information. Leadership engagement, which in this case measured the FBO's leaders' involvement in health- and intervention-related activities, was determined by survey. The availability of resources including both the physical space dedicated for implementation activities and the human resources - namely congregants who were willing to volunteer and to be trained as CHAs to deliver the intervention. In addition to the leader's report of the availability of physical resources and health personnel, site visits were made by the Principal Investigator of the study to all FBOs to identify and verify the availability of spaces; and the study was introduced to the general congregation at major services and any adult member of the FBO was eligible to volunteer for the $\mathrm{CHA}$ training course; no previous training or experience was required. The 3 rd element in readiness is access to intervention-related information; this was determined from the CHA's evaluation of their training modules and the provided supporting educational material.

(b) Individual's attitude toward the intervention included the CHAs' perception of their roles, and the FBO leaders' and CHAs' perception of how potential clients might respond to the intervention. This was determined by survey.

(c) Individual stage of change: The trans-theoretical model of change (TTM) comprises 5 change stages: (1) pre-contemplation - no acknowledgment of a problem, (2) contemplation - an acknowledgement of a need for change, (3) preparation - the intention to act, (4) action - sustaining the change for at least $6 \mathrm{mths}$ and (5) maintenance - sustaining the change for $>6 \mathrm{mths}$. Here, we utilized the TTM to map the FBOs' leaders' intent to effect health-related activities within their respective congregations.

\section{iii) Development of assessment tools}

To guide our initial interview with the FBO leadership, we adapted a survey that was developed by the CONTACT study team in Guyana (24). Our adapted survey contained 30 questions of mainly multiple choice format; questions requiring short answers were transcribed verbatim. Thirteen questions focussed on the readiness for implementation: 6 determined leadership engagement, 6 assessed the available resources and 1 measured individuals' attitude toward the implementation strategy (Table 1). 
Table 1

- The FBOs leaders' estimation of the readiness of the FBOs to implement the intervention

\section{Domains of Assessment Question Readiness}

Leadership

1. Do you have teaching sessions on health related issues

engagement

2. Which health-related issues have been taught in the last year

3. Does your place of worship have an ongoing programme for persons living with diabetes

4. Does your place of worship have an ongoing programme to reduce risk factors for diabetes? E.g. health eating, active lifestyle (Emphasis here on prevention)

5. Does your congregation have any plans for implementing new, or improving on existing health-related activities?

6. Do you see a need for a diabetes health promotion and prevention programme within your congregation?

Available $\quad$ 1. Do you have a small enclosed room where the CHA can see members in private?

resources

(physical

space)

2. Do you have resources and facilities for secure and organised record keeping

Available

resources

(human

resources)

3. Do you have resources and facilities for cooking classes?

1. Does your congregation have someone who oversees health-related matters?

2. Does he/she have any formal qualifications for the position? E.g. health professional / work experience in the medical field

3. Are any (other) of your congregation members trained in health?

Individuals' 1. Do you believe congregation members would utilise the services of a HA chosen attitudes from among them?

A second survey was created in RedCap and distributed online via email to CHA 4-6wks after the completion of the CHA training. The survey consisted of 11 questions, formatted on a 5-point Likert scale; from strongly disagree to strongly agree. Seven questions assessed access to intervention-related information by asking their perceptions of the content and delivery of the course material, and four questions assessed their views of the attitude that potential clients might have towards the programme.

\section{(2) Implementation of the CHA training programme}

Once FBO readiness was ascertained, all FBO members who volunteered were invited to the $\mathrm{CHA}$ course. Volunteers indicated if they had any previous training in healthcare. The CHA course was carried out on the FBO compound and included didactic lectures and practical exercises in weight, blood pressure (BP) and blood glucose measurements, dietary history taking, electronic data entry, cooking and ethics (Table 2). This was followed by a simulation with volunteer 'patients' and a practical assessment by external examiners. Each skill was judged separately and CHAs had to show competence in order to be certified. The entire schedule required $2 \mathrm{hrs}$ weekly for 10 wks. Effectiveness of the CHA training programme was determined from the success rates at the summative assessment. The odds of being 
successful at a particular station for persons with previous health care experience versus those without health care experience was also calculated. The statistical significance of the differences was explored using Fisher's exact test. 
Table 2

The CHA training programme

\begin{tabular}{|c|c|c|c|c|}
\hline Session & Core Topics & Format & $\begin{array}{l}\text { Mode of } \\
\text { delivery }\end{array}$ & Resources \\
\hline 1 & $\begin{array}{l}\text { What I need to know about T2DM } \\
\text { The T2DM prevention, remission and } \\
\text { referral protocol } \\
\text { How to measure waist \& hip } \\
\text { circumferences }\end{array}$ & $\begin{array}{l}\text { Lecture, } \\
\text { discussion } \\
\text { practical }\end{array}$ & $\begin{array}{l}\text { Face to face, } \\
\text { online } \\
\text { resources }\end{array}$ & $\begin{array}{l}\text { Computer } \\
\text { Measuring } \\
\text { tape }\end{array}$ \\
\hline 2 & $\begin{array}{l}\text { The physiology of T2DM remission } \\
\text { How to measure waist \& hip } \\
\text { circumferences (repeat) } \\
\text { How to perform blood pressure } \\
\text { measurements }\end{array}$ & $\begin{array}{l}\text { Lecture, } \\
\text { discussion } \\
\text { practical }\end{array}$ & $\begin{array}{l}\text { Face to face, } \\
\text { online } \\
\text { resources }\end{array}$ & $\begin{array}{l}\text { Measuring } \\
\text { tape } \\
\text { Automated } \\
\text { BP monitor }\end{array}$ \\
\hline 3 & $\begin{array}{l}\text { How to take a take a history including } \\
\text { weekly food intake and medication } \\
\text { adherence } \\
\text { How to perform blood pressure } \\
\text { measurements (repeat) } \\
\text { How to perform a weight measurement }\end{array}$ & practical & $\begin{array}{l}\text { Face to face, } \\
\text { online } \\
\text { resources }\end{array}$ & $\begin{array}{l}\text { Automated } \\
\text { BP monitor } \\
\text { scale }\end{array}$ \\
\hline 4 & $\begin{array}{l}\text { How to perform a blood sugar using the } \\
\text { point-of-care machine } \\
\text { How to use the RedCap database }\end{array}$ & practical & $\begin{array}{l}\text { Face to face, } \\
\text { Online } \\
\text { resources }\end{array}$ & $\begin{array}{l}\text { Glucometer } \\
\text { computer }\end{array}$ \\
\hline 5. & $\begin{array}{l}\text { How to perform a blood sugar using the } \\
\text { point-of-care machine (repeat) } \\
\text { How to perform a weight measurement } \\
\text { (repeat) }\end{array}$ & $\begin{array}{l}\text { Practical } \\
\text { Practical }\end{array}$ & $\begin{array}{l}\text { Face to face, } \\
\text { Online } \\
\text { resources }\end{array}$ & $\begin{array}{l}\text { Glucometer } \\
\text { scale }\end{array}$ \\
\hline 6. & Review of all practical demonstrations & Practical & $\begin{array}{l}\text { Face to face, } \\
\text { Online } \\
\text { resources }\end{array}$ & $\begin{array}{l}\text { All the } \\
\text { above }\end{array}$ \\
\hline 7. & Simulation & Practical & Face to face & $\begin{array}{l}\text { All the } \\
\text { above } \\
\text { Volunteer } \\
\text { 'patients' }\end{array}$ \\
\hline 8 & Assessment & $\begin{array}{l}\text { OSCE } \\
\text { format }\end{array}$ & Face to face & $\begin{array}{l}\text { All the } \\
\text { above } \\
\text { Volunteer } \\
\text { 'patients' }\end{array}$ \\
\hline
\end{tabular}




\begin{tabular}{|lllll|}
\hline Session & Core Topics & Format & $\begin{array}{l}\text { Mode of } \\
\text { delivery }\end{array}$ & Resources \\
\hline 9. & Cookery & Practical & Face to face & $\begin{array}{l}\text { Equipped } \\
\text { kitchen, } \\
\text { food }\end{array}$ \\
\hline 10. & Ethics & $\begin{array}{l}\text { Online } \\
\text { resources }\end{array}$ & \\
\hline
\end{tabular}

\section{(3) LCD Intervention for eligible participants}

Once the CHAs were trained, a health event was held on the FBO compound where interested persons could be screened for intervention eligibility. The invitation was initially extended to congregants and then a snowball effect was added. The intervention was a longitudinal study design with measurements recorded pre, during and post the LCD. The inclusion criteria were: age $20-69$ years, $B M I \geq 27 \mathrm{~kg} / \mathrm{m} 2$ and a diagnosis of T2DM for $<6$ years or a diagnosis of pre-diabetes. The exclusion criteria were similar to those of the BDRS1 protocol (14). Eligible persons went through the informed consent process. Potential participants who were eligible based on age and BMI but were unsure of their glucose status were also consented and then screened for glucose status using the oral glucose tolerance test (OGTT) and A1C. The American Diabetes Association (ADA) guidelines were used to determine eligibility.

The daily dietary allowance was restricted to $840 \mathrm{cal}$ consisting of 4 bottles of Glucerna ${ }^{\circledR}(180 \mathrm{cal}$ per bottle (8oz)), 4 portions of non-starchy vegetables (30cal each) and at least $3 \mathrm{~L}$ of non-calorie beverages. The intervention period was 12 weeks. On the first day of the intervention all participants discontinued all anti-diabetic medication. Baseline BP, FBG and weights were done by their attending $\mathrm{CHAs}$ at the FBO and repeated weekly for the 12-week duration. A1C was done at week 12 . A dietary history was taken to monitor compliance. Induction of remission was defined by the week 12 glucose measurements. For persons with $\mathrm{T} 2 \mathrm{DM}$, this was represented as an $\mathrm{A} 1 \mathrm{C}<6.5 \%$ or a $\mathrm{FBG}$ of $<7 \mathrm{mmol} / \mathrm{I}$ whilst off of their antidiabetes medication for the 12-week study duration. For pre-diabetes participants, remission was defined as normalisation of blood glucose i.e. an $\mathrm{A} 1 \mathrm{C}$ of $<5.7 \%$ or a $\mathrm{FBG}$ of $<5.6 \%$.

The continuous variables of weight, $\mathrm{HbA1C}$, FBG, systolic BP (SBP) and diastolic BP (DBP) and the change in these measurement at post intervention was analysed in Stata and presented as the mean ( $95 \%$ confidence interval). Differences by sex and by glucose status was also explored.

\section{Ethical considerations}

The study was approved by the joint Ministry of Health / The University of the West Indies Institutional Review Board.

\section{Results}

\section{Pre-implementation}


Of the 3 FBOs selected, 2 were located on the outskirts of Bridgetown - the capital of Barbados, while the third was located in a rural community.

\section{An engaged leadership}

All 3 churches have taught on health-related issues at some time in the past; 2 sites had sessions in the last year - both had talks on cancer. In addition, one site organised a series of NCD-related talks on diabetes, obesity, exercise and nutrition. The same site has an ongoing programme for prevention of NCDs in the form of a bi-weekly fitness group. All 3 sites indicated intentions of improving or implementing new health programmes but no strategic policies had been documented or enacted. Leaders at all sites were receptive to the idea of a diabetes prevention programme and reported perceptions that there was a high burden of NCDs in their community. Leaders also expressed feeling a responsibility to the congregation and communities to not only offer spiritual guidance but support towards physical health as well. They described this intervention as 'timely' and 'necessary'.

\section{Adequate resources}

The leaders reported that the physical plants were adequate with private space for interviews and secure storage facilities. All but one of the facilities had a designated area for cooking activities. A site visit performed by the lead investigator confirmed these reports.

During the interviews, the organizational leaders across the 3 churches identified several health professionals amongst the congregation: 20 nurses, 7 physicians, 2 physiotherapists, 1 paramedic and 6 community health aides with care of the elderly experience; however, the sites had neither structured health programmes nor designated health leaders.

In response to the request for volunteers, 40 persons volunteered for training: 20 with no previous health experience, 9 nurses, 4 doctors, 3 first aiders, 1 pharmacist, 1 social worker, 1 paramedic and 1 community health aide.

\section{Easy Access to intervention characteristics}

Sixteen CHAs responded to the access to intervention-related information survey: 9 nurses, 2 of whom were retired and 2 in training; 3 persons with no health training, 2 with care of the elderly exposure, 1 paramedic and 1 first aider. Responses were condensed from the 5-point Likert scale (strongly agree, agree, neutral, disagree, strongly disagree) to a 3-point scale (agree, neutral, disagree) for easy reporting (Table 3). The majority of answers indicated that the content and delivery was adequate. One responder mentioned the need for additional dietary information including dietary allowances and menus. Another person thought that the time allotted to the course was inadequate especially for persons who had no previous health exposure; interestingly, all persons who had no previous exposure agreed that the time allotted to the course was adequate. One person disagreed that their knowledge and skills base was expanded while on this course; in each case, the person had previous health training. 
Table 3

Responses of CHAs on the content, delivery and acceptability of the intervention

\section{Question n (\%)}

1. The content of the course was of an acceptable standard

2. The information was delivered in such a way that it was difficult to understand

3. The time allotted to the course was adequate

4. My knowledge base was expanded while on this course

5. My skills base was expanded while on this course

6. The course is good enough to be offered for a fee

7. I am likely to recommend this course to a friend or colleague should it become publicly available

8. Seeing participants according to the intervention schedule will disrupt the church schedule

9. Seeing participants according to the intervention schedule fits into my schedule

10. Utilising the church as the intervention site is convenient for participants

11. Utilising the church as the intervention site hinder participants from freely sharing information agree neutral

disagree
15

(94)

$1(6) \quad 0$

$15(94)$
$1(6)$

1 (6)

(88)

14

(88)

1 (6)

1 (6)

1 (6)

15

(94)

0

1 (6)

13

(81)

3 (19)

$0(0)$

16

(100)

0

0 (0)

0 (0)

3 (19)

$13(81)$

13

(81)

3 (19)

0 (0)

15

(94)

1 (6)

$0(0)$

0 (0)

2 (12)

14 (88)

\section{Individuals' attitudes to the intervention}

There were mixed reactions from the FBO leaders regarding the congregations' utilisation of health services of $\mathrm{CHAs}$ chosen from among them; two sites answered in the affirmative and the other was unsure. CHAs however, unanimously agreed that the FBO was a convenient and acceptable location for clients and that the schedule was not disruptive to the FBO or to themselves. This was confirmed by that attendance register which showed that all clinical measurement stations were covered by CHAs over the intervention period, barring one visit at one site during a church convention when the facility was closed and $\mathrm{CHA}$ and participants were away from the site.

In addition, the participant register showed high attendance throughout the study. Three participants prematurely discontinued the intervention; 1 at week 3 and 1 at week 10 , both due to travel and another 1 at week 6 who was no longer interested in continuing; all 3 had pre-diabetes. The lowest attendance of $82 \%$ occurred during the convention week; apart form that, the lowest attendance was $89 \%$ at weeks 8 
and 11. There were 21 absences in all (out of 429 visits); 1 absence occurred in 5 people, 2 in 2 people, 3 in 1 person, 4 in 1 person and 5 in 1 person.

\section{A changing organisation}

When applying the TTM to the leaders' and by extension, the organizations' intent to change; leaders have used the opportunities afforded via this study to progress from the contemplation phase to the preparation phase i.e. from a point where there was no concerted effort to rectify the health challenges in their organisation to a place where they have facilitated the assembly of a team of CHAs to support the intervention.

\section{Implementation}

\section{Community Health Advocates}

Forty persons volunteered for the CHA training program (35 females: 5 males); of these, 32 ( $80 \%$ ) attended at least 1 session. Four of the 32 discontinued the program during the first 2 weeks; the reasons were: work commitments, family commitments, change in church membership and the program was not what was expected. The remaining 28 (70\%) completed the training and $27(68 \%)$ of these took the clinical assessment; 10 at 2 sites and 7 at the third site. Of those 27,14 had previous health worker experience including paramedics, nurses and clinicians.

\section{Implementation Effectiveness}

Amongst those who took the competence examination, the success rate for each station was: BP (100\%), weight (93\%) [2 persons were not assessed and hence failed by default; all who were assessed passed], hip circumference (89\%), waist circumference (78\%) and glucose (74\%). All CHA passed at least 1 station. The odds of success were better in persons with previous clinical training only at the glucometer station $(\mathrm{OR}=8.3,1-224 ; \mathrm{p}=0.05)$ (Table 4). 
Table 4

Percentage success rate at each clinical measurement station for Community Health Advocates with previous health care experience vs those with no experience

\begin{tabular}{|llll|}
\hline & Experience (\%) & No experience (\%) & OR $(95 \%$ Cl) \\
\hline waist & 85 & 71 & $2.1(0.3,19.8)$ \\
\hline hip & 92 & 93 & $0.9(0.02,38.9)$ \\
\hline weight & 100 & $85^{\star}$ & $5.3(0.4,198.0)$ \\
\hline glucose & 92 & 57 & $8.3(1.0,224)$ \\
\hline BP & 100 & 100 & 1 \\
\hline * 2 (15\%) & persons did not take the test and hence failed by default \\
\hline
\end{tabular}

\section{Intervention Effectiveness}

One hundred and fifty-six persons were interviewed over a 6-month period; 15 were immediately eligible; of these 13 participated; the other 2 migrated. An additional 77 persons were potentially eligible based on age and BMl; 64 attended their appointments for screening for glucose status and of these 18 were enrolled.

In all, 31 participants were enrolled across the $3 \mathrm{FBOs}$; further recruitment was interrupted by the lockdown due to COVID19 pandemic. There were 28 (90\%) females and $3(10 \%)$ males, 11 (35\%) with T2DM (10f: $1 \mathrm{~m})$, of whom 3 were diagnosed during screening for this study, all female. The 8 persons who were previously diagnosed were all on glucose-lowering medication; 7 on metformin; 3 of these in combination with a sulphonylurea and 2 with a dipeptidyl peptidase-4 (DPP-4) inhibitor; 1 person was on a sodium-glucose cotransporter-2 (SGLT-2) inhibitor alone. Twenty participants (65\%) were enrolled with pre-diabetes, 13 were diagnosed during screening for this study $(12 \mathrm{f}: 1 \mathrm{~m}) ; 3$ of the 7 who were previously diagnosed were on glucose-lowering medication; all 3 on metformin, 1 in combination with a DPP-4 inhibitor. Eleven participants had a history of HTN; all were on anti-HTN medication. Nine participants had a history of high cholesterol, 4 were on HMG-CoA reductase inhibitors.

Average entry measurements were as such mean $(95 \% \mathrm{Cl})$ : weight $(\mathrm{kg}) 93.7$ (86.2 to 101.1) 90.6 in females vs. 116.0 in males; FBG (mmol/l) was 6.4 (6.1 to 6.7); 6.6 in T2DM vs. 6.3 in pre-diabetes and $\mathrm{HbA1C}$ was $6.6 \%$ (6.3 to 6.9 ); $6.6 \%$ in both T2DM and pre-diabetes (Table 5). 
Table 5

Change in weight, FBG and $\mathrm{HbA} 1 \mathrm{C}$ post $\mathrm{LCD}$ intervention

\begin{tabular}{|llll|}
\hline & $\begin{array}{l}\text { Pre-intervention } \\
\text { Med (IQR) }\end{array}$ & $\begin{array}{l}\text { Post-intervention } \\
\text { Med (IQR) }\end{array}$ & $\begin{array}{l}\text { Change } \\
\text { Med (IQR); p value }\end{array}$ \\
\hline HbA1C (\%) [all] & $6.3(6.0-6.9)$ & $6.2(5.8-6.5)$ & $0.2(0-0.6) ; p=0.0004$ \\
\hline HbA1C (\%) [T2DM] & $6.7(6.2-7.1)$ & $6.2(5.9-6.7)$ & $0.3(0.2-0.6)$ \\
\hline HbA1C (\%) [predb] & $6.2(6.0-6.5)$ & $6.2(5.8-6.5)$ & $0.1(-0.1-0.5)$ \\
\hline FBG (mmol/L) [all] & $6.3(5.8-6.9)$ & $6.0(5.4-6.4)$ & $0.4(-0.1-0.9) ; p=0.01$ \\
\hline FBG (mmol/L) [T2DM] & $6.6(6.0-7.1)$ & $6.3(6-6.8)$ & $0.4(-0.4-0.8)$ \\
\hline FBG (mmol/L) [predb] & $6.2(5.8-6.6)$ & $6.0(5.4-6.3)$ & $0.4(-0.1-0.9)$ \\
\hline Weight (kg) [all] & $92.5(79.8-101.6)$ & $88.2(72.5-95.3)$ & $7.6(4.5-8.8) ; p<0.00001$ \\
\hline Weight (kg) [male] & $117.1(104.0-128.7)$ & $106.0(97.0-118.2)$ & $9.8(6.3-10.5)$ \\
\hline Weight (kg) [female] & $91.6(78.0-100.6)$ & $87.0(71.7-94.8)$ & $7.2(4.6-8.6)$ \\
\hline
\end{tabular}

Mean $(95 \% \mathrm{Cl})$ change post-intervention was as such: weight loss $6.8 \mathrm{kgs}(5.4$ to 8.2$), \mathrm{p}<0.00001 ; 7.9 \mathrm{kgs}$ $(-3.4$ to 19.2$)$ in males vs $6.6 \mathrm{kgs}$ (5.2 to 8.1$)$ in females. FBG ( $\mathrm{mmol} / \mathrm{l})$ reduction was $0.4(0.1$ to 0.7$), p=$ $0.004 ; 0.5 \mathrm{mmol} / \mathrm{I}(0.1$ to 0.8$)$ in persons with prediabetes and $0.3(-0.3$ to 0.8$)$ in persons with T2DM. $\mathrm{HbA} 1 \mathrm{C}$ decreased by $0.4 \%(0.1$ to 0,7$), \mathrm{p}=0.003$; with a similar reduction in both persons with prediabetes and T2DM. SBP and DBP decreased by $10 \mathrm{mmHg} ; p=0.003$ and $8 \mathrm{mmHg} p=0.005$ respectively.

Of the 11 persons with T2DM who completed the LCD intervention, 10 persons were available for FBG and $\mathrm{HbA} 1 \mathrm{C}$ testing at week 12. Based on an $\mathrm{HbA} 1 \mathrm{C}$ threshold of $<6.5 \%, 6(60 \%)$ were in remission. Based on the FBG of $<7 \mathrm{mmol} / \mathrm{l}, 9(90 \%)$ were in remission.

Of the 20 persons with pre-diabetes, 17 completed the study and were available for $\mathrm{HbA} 1 \mathrm{C}$ testing at week 12; only 15 were fasted and hence had FBG done. Based on an HbA1C threshold of $<5.7 \%, 3$ (18\%) reverted to normal glucose status. Based on FBG, $6(40 \%)$ reverted to normal glucose status $(<5.6$ $\mathrm{mmol} / \mathrm{L}) .1$ person achieved normal glucose status by both FBG and $\mathrm{HbA1C}$.

Five of the 11 participants that were anti-hypertensive medications either decreased or discontinued the medication.

\section{Discussion}

\section{Pre-implementation}

When assessing readiness, we found high levels of leadership engagement, adequate resources and high health literacy among CHAs. If mapped along the trans-theoretical model of change (TTM), the act of engaging leaders during a community-based participatory methodology afforded them the opportunity to 
progress from the contemplation phase - an acknowledgement of a need for change, to the preparation phase - the intention to act. Action, the next step in the TTM, would be defined here by a continuation of the CHA-led intervention for at least 6 months. Conscious awareness is one of the change processes that facilitate action; this can be achieved via educational activities on NCDs particularly on the burden of disease within the population and the impact the intervention can make to the improvement on NCD management (25). The ground work has already been established as is evidenced by the acceptability of the NCD education and other intervention-related activities delivered to the CHA during their training. Long term maintenance can be facilitated by the process of stimulus control, which is the provision of an environment that is conducive to the continuation of the intervention. In this study, maintenance has been facilitated as the glucometers, blood pressure kits, dietary booklets and other material that were provided during training will be available to the CHA for use after the study is completed. The TTM has been used to expound on the changes in individual behaviours across a wide range of practices including lifestyle modification for the management of NCDs (26-28). Within the recent scientific literature, the TTM has also been proposed as a framework for organisational change and community coalitions $(29,30)$. More emphasis should be placed on leadership engagement within the community not simply as a facilitator of the intervention but as an agent of change.

\section{Implementation}

The results suggest that the combination of trained CHAs within the context of a FBO is a useful implementation strategy in conducting a diabetes remission intervention. Theoretical barriers to implementation, such as human resources and infrastructural limitations, were not found to be present in the pre-implementation phase, where high levels of leadership engagement contributed to the state of readiness (31). There was a high $\mathrm{CHA}$ retention rate, even in the face of a formal summative assessment prior to certification. The intervention-delivery training method was found to be acceptable and sufficiently thorough for $100 \%$ of trainees to achieve competence in $\geq 1$ of the 5 clinical skills necessary to monitor the anthropometric and biochemical measures necessary. Extra attention, however, should be focused on glucometer competency in those with no previous healthcare experience. Despite reports of the effectiveness of CHA interventions in NCD management, there are concerns regarding unregulated $\mathrm{CHA}$ action and adverse patient outcome resulting from uncoordinated care $(16,32-34)$ We were able to circumvent these critical issues by having a licensed medical practitioner as a member of the community to provide oversight to major clinical decisions.

The Chronic Care Model provides the evidence base for the growing recognition that NCD management requires integration of clinic-based and community-supported care. Whereas FBOs are being used increasingly as community hubs for health interventions, particularly in African descent populations, the results of the work are transferable on the theoretical level; where the FBOs represent "a safe space" to conduct the intervention through charitable means and the CHAs are broadly categorized as "volunteers" who have the willingness and capacity to be trained $(35,36)$.

\section{Intervention}

Page $15 / 21$ 
Being female is a social determinant for obesity and development of T2DM in the Caribbean; genderspecific interventions are therefore warranted. In this study $90 \%$ of participants were females, hence FBO may be an ideal location to engage those most at risk.

Eighty percent of participants with pre-diabetes were newly diagnosed. Mathematical models predict that pre-diabetes to T2DM conversion occurs at approximately 2.5\%/year, with persons of African and Asian descent being at higher risk $(3,36)$. Pre-diabetes management hinges on weight loss, and a substantial amount of work has investigated the effects of various diets $(37,38)$. In this study, participants with prediabetes were on average, able to surpass the recommended $5 \%$ reduction in body weight needed for T2DM risk reduction. In the absence of a community-based intervention, diagnosis may have been delayed or remained undiagnosed until symptomatic. We therefore recommend community-based screening for pre-diabetes and intensive dietary intervention for T2DM risk reduction and pre-diabetes remission.

In a consensus statement by Buse et al, remission of T2DM was characterised by both glucose levels and length of time (28). Partial remission was defined as maintenance of 'sub-diabetic hyperglycaemia' $\mathrm{HbA} 1 \mathrm{C}=5.7-6.4 \%$ or $\mathrm{FBG}=5.6-6.9 \mathrm{mmol} / \mathrm{I}-$ for at least 1 year without any ongoing therapy, whereas complete remission was defined as normalization of glucose measurements $-\mathrm{HbA} 1 \mathrm{C}<5.7 \%$ or $\mathrm{FBG}<$ $5.6 \mathrm{mmol} / \mathrm{l}-$ for at least 1 year without any ongoing therapy. There was no consideration given to prediabetes remission. Of the 10 persons with T2DM in this study, 3 achieved induction of complete remission, whereas the other seven achieved induction of partial remission. Follow-up measurements at one year would be necessary to investigate the maintenance of this effect. Remission rates as defined by $\mathrm{HbA} 1 \mathrm{C}$ were lower at $60 \%$ than by FBG $(90 \%)$, this is in keeping with previous studies in both the Barbadian and the African American population which showed that for any given level of FBG, HbA1Cs levels tend be higher $(39,40)$.

Maintenance of weight loss is necessary to accrue maximum cardiovascular benefits; in order to achieve this, continuing lifestyle management including intensive dietary advice is necessary. For a communitybased intervention, this can be achieved via two mechanisms: (1) training the CHAs in nutrition and dietetics; this would potentially increase capacity and accessibility to dietary advice (2) formalizing relationships with surrounding health centres; this would allow for referral to trained dietician and any additional services e.g. podiatry and ophthalmology, however, this avenue is limited by the availability of appointments.

In conclusion, this feasibility study supports the proposal that weight loss due to a LCD can induce diabetes and pre-diabetes remission in a community context; as the FBO-based, CHA-supported implementation strategy was acceptable to all parties involved. A notable limitation of this study is that it was heavily subscribed by women; although gender-specific interventions are warranted, future studies could involve adaptation of this methodology to other community sites with the prospects of attracting a more balanced cohort. Although the small sample size may limit generalisability at the population level, the emerging themes are transferable on a theoretical level to other settings and may inform the scale up 
of community-based participatory research. Additional studies can consider how this protocol can be adapted to an online version to mitigate against interruptions due to social distancing and lockdown protocols.

\section{Declarations}

Ethics approval: This study was approved by the joint The University of the West Indies / Ministry of Health Institutional Review Board. 180301A.

Consent to participate: $\mathrm{n} / \mathrm{a}$

Consent for publication: $\mathrm{n} / \mathrm{a}$

Availability of data and materials: The datasets used and/or analysed during the current study are available from the corresponding author on reasonable request.

Competing interests: The authors declare that they have no competing interests.

Funding: Funding was provided by the Massy Foundation (Barbados) Inc. The funders did not have a role in the design of the study or the collection, analysis, and interpretation of data or in writing the manuscript.

\section{Authors' contribution:}

$\mathrm{KQ}$ contributed to the design of the work, the acquisition, analysis, and interpretation of data and writing the draft and final manuscript.

NSG contributed to the acquisition and analysis of data and writing the draft and final manuscript.

CG contributed to the acquisition and interpretation of data and writing the draft manuscript.

NG contributed to the design of the work, the interpretation of data and the writing the draft and final manuscript.

FBJ contributed to the acquisition of data and writing the draft manuscript.

AS contributed to the design of the work and writing the draft manuscript.

All authors read and approved the final manuscript.

Acknowledgements: $n / a$

\section{References}

1. IDF DIABETES ATLAS. International Diabetes Federation; 2019. 
2. Crandall JP, Knowler WC, Kahn SE, Marrero D, Florez JC, Bray GA, et al. The prevention of type 2 diabetes. Nature clinical practice Endocrinology \& metabolism. 2008;4(7):382-93.

3. Yokota N, Miyakoshi T, Sato Y, Nakasone Y, Yamashita K, Imai T, et al. Predictive models for conversion of prediabetes to diabetes. J Diabetes Complications. 2017;31(8):1266-71.

4. Kim YA, Ku EJ, Khang AR, Hong ES, Kim KM, Moon JH, et al. Role of various indices derived from an oral glucose tolerance test in the prediction of conversion from prediabetes to type 2 diabetes. Diabetes Res Clin Pract. 2014;106(2):351-9.

5. Leandro CG, da Fonseca E, de Lim CR, Tchamo ME, Ferreira ESWT. Barriers and Enablers That Influence Overweight/Obesity/Obesogenic Behavior in Adolescents From Lower-Middle Income Countries: A Systematic Review. Food and nutrition bulletin. 2019:379572119853926.

6. Mancini MC, Halpern A. Orlistat in the prevention of diabetes in the obese patient. Vascular health and risk management. 2008;4(2):325-36.

7. Buchanan TA, Xiang AH, Peters RK, Kjos SL, Marroquin A, Goico J, et al. Preservation of Pancreatic $\beta$ Cell Function and Prevention of Type 2 Diabetes by Pharmacological Treatment of Insulin Resistance in High-Risk Hispanic Women. Diabetes. 2002;51(9):2796-803.

8. Obesity and overweight. World Health Organization; 2016.

9. NCDs at a Glance: NCD Mortality and Risk Factor Prevalence in the Americas Pan American Health Organization; 2019.

10. Guariguata L, Brown C, Sobers N, Hambleton I, Samuels TA, Unwin N. An updated systematic review and meta-analysis on the social determinants of diabetes and related risk factors in the Caribbean. Revista panamericana de salud publica = Pan American journal of public health. 2018;42:e171.

11. Batterham RL, Cummings DE. Mechanisms of Diabetes Improvement Following Bariatric/Metabolic Surgery. Diabetes care. 2016;39(6):893-901.

12. Lim EL, Hollingsworth KG, Aribisala BS, Chen MJ, Mathers JC, Taylor R. Reversal of type 2 diabetes: normalisation of beta cell function in association with decreased pancreas and liver triacylglycerol. Diabetologia. 2011;54(10):2506-14.

13. Taylor R, Leslie WS, Barnes AC, Brosnahan N, Thom G, McCombie L, et al. Clinical and metabolic features of the randomised controlled Diabetes Remission Clinical Trial (DiRECT) cohort. Diabetologia. 2018;61(3):589-98.

14. Bynoe K, Unwin N, Taylor C, Murphy MM, Bartholomew L, Greenidge A, et al. Inducing remission of Type 2 diabetes in the Caribbean: findings from a mixed methods feasibility study of a low-calorie liquid diet-based intervention in Barbados. Diabetic medicine : a journal of the British Diabetic Association. 2019.

15. Joshi R, Alim M, Kengne AP, Jan S, Maulik PK, Peiris D, et al. Task shifting for non-communicable disease management in low and middle income countries--a systematic review. PloS one. 2014;9(8):e103754.

16. Jeet G, Thakur JS, Prinja S, Singh M. Community health workers for non-communicable diseases prevention and control in developing countries: Evidence and implications. PloS one. 
2017;12(7):e0180640.

17. Schoenthaler AM, Lancaster KJ, Chaplin W, Butler M, Forsyth J, Ogedegbe G. Cluster Randomized Clinical Trial of FAITH (Faith-Based Approaches in the Treatment of Hypertension) in Blacks. Circ Cardiovasc Qual Outcomes. 2018;11(10):e004691.

18. Lancaster KJ, Carter-Edwards L, Grilo S, Shen C, Schoenthaler AM. Obesity interventions in African American faith-based organizations: a systematic review. Obes Rev. 2014;15 Suppl 4:159-76.

19. WHO. Noncommunicable diseases country profiles. 2018.

20. Unwin N, Rose AMC, George KS, Hambleton IR, Howitt C. The Barbados Health of the Nation Survey: Core Findings. Miller Publishing Company. Edgehill, St. Thomas, Barbados, West Indies: The Ministry of Health of the Barbados Government and the Chronic Disease Research Centre, The UWl; 2015.

21. Institute for Health Metrics and Evaluation. Global Health Data Exchange: GBD Results Tool. 2019.

22. Faith-based collaboration to counteract chronic diseases 2014 [Available from: http://www.barpbb.com/images/resources/Declaration-of-Bridgetown.pdf.

23. Samuels TA, Unwin N. The 2007 Caribbean Community Port-of-Spain Declaration on noncommunicable diseases: an overview of a multidisciplinary evaluation. Revista panamericana de salud publica $=$ Pan American journal of public health. 2018;42:e193.

24. New group looking to target Non-Communicable Diseases through religious organisations. In: Information DoP, editor. Guyana2017.

25. Abdel-All M, Putica B, Praveen D, Abimbola S, Joshi R. Effectiveness of community health worker training programmes for cardiovascular disease management in low-income and middle-income countries: a systematic review. BMJ open. 2017;7(11):e015529.

26. Mastellos N, Gunn LH, Felix LM, Car J, Majeed A. Transtheoretical model stages of change for dietary and physical exercise modification in weight loss management for overweight and obese adults. The Cochrane database of systematic reviews. 2014(2):Cd008066.

27. Marcus BH, Simkin LR. The transtheoretical model: applications to exercise behavior. Medicine and science in sports and exercise. 1994;26(11):1400-4.

28. Tseng HM, Liao SF, Wen YP, Chuang YJ. Stages of change concept of the transtheoretical model for healthy eating links health literacy and diabetes knowledge to glycemic control in people with type 2 diabetes. Primary care diabetes. 2017;11(1):29-36.

29. Prochaska JM, Prochaska JO, Levesque DA. A transtheoretical approach to changing organizations. Administration and policy in mental health. 2001;28(4):247-61.

30. Finnegan HA, Langhinrichsen-Rohling J, Blejwas E, Hill A, Ponquinette D, Archer S, et al. Developing a Productive Workgroup Within a Community Coalition: Transtheoretical Model Processes, Stages of Change, and Lessons Learned. Progress in community health partnerships : research, education, and action. 2018;12(1s):61-72.

31. Quimby KR., Jordan T., George C., Sobers N., I. H, editors. Assessing the readiness of faith-based organisations as sites for the Barbados Diabetes Remission Study 2 - a community-based diabetes 
remission intervention. . 64th Annual CARPHA Health Research Conference; 2019; Trinidad and Tobago.

32. Hughes MM, Yang E, Ramanathan D, Benjamins MR. Community-Based Diabetes Community Health Worker Intervention in an Underserved Chicago Population. Journal of community health. 2016;41(6):1249-56.

33. Brown LD, Vasquez D, Salinas JJ, Tang X, Balcazar H. Evaluation of Healthy Fit: A Community Health Worker Model to Address Hispanic Health Disparities. Preventing chronic disease. 2018;15:E49.

34. van de Ruit C. Unintended Consequences of Community Health Worker Programs in South Africa. Qualitative health research. 2019:1049732319857059.

35. Dodani S, Sullivan D, Pankey S, Champagne C. HEALS: A Faith-Based Hypertension Control and Prevention Program for African American Churches: Training of Church Leaders as Program Interventionists. Int J Hypertens. 2011;2011:820101.

36. Fazli GS, Moineddin R, Bierman AS, Booth GL. Ethnic variation in the conversion of prediabetes to diabetes among immigrant populations relative to Canadian-born residents: a population-based cohort study. BMJ open diabetes research \& care. 2020;8(1).

37. Guess ND. Dietary Interventions for the Prevention of Type 2 Diabetes in High-Risk Groups: Current State of Evidence and Future Research Needs. Nutrients. 2018;10(9).

38. Amer OE, Sabico S, Alfawaz HA, Aljohani N, Hussain SD, Alnaami AM, et al. Reversal of Prediabetes in Saudi Adults: Results from an 18 Month Lifestyle Intervention. Nutrients. 2020;12(3).

39. Unwin N, Howitt C, Rose AM, Samuels TA, Hennis AJ, Hambleton IR. Prevalence and phenotype of diabetes and prediabetes using fasting glucose vs $\mathrm{HbA} 1 \mathrm{c}$ in a Caribbean population. J Glob Health. 2017;7(2):020407.

40. Herman WH, Ma Y, Uwaifo G, Haffner S, Kahn SE, Horton ES, et al. Differences in A1C by race and ethnicity among patients with impaired glucose tolerance in the Diabetes Prevention Program. Diabetes care. 2007;30(10):2453-7.

\section{Figures}


(i) Purposive selection of FBOs

- Registered medical practitioner

- Congregation $>100$

(ii) Definition of implementation outcomes (CFIR)

-Readiness:

-Engagement

-Resources

-access to material

-Individuals attitude towards the intervention

-Individual / organisational change state

(iii) Development of the assessment tools

-FBO survey

-Engagement

-resources

-attitude

- $\mathrm{CHA}$ survey

-Attitude

-Access to material

CHA training course:

2 hrs weekly $x 10$

weeks

Assessment in weight, BP, and FBG

measurement skills

Implementation effectiveness
LCD for eligible participants

Weekly weight, BP and FBG

measurement $x 12$ weeks

Clinical Effectiveness

\section{Figure 1}

Pre-implementation, Implementation and Intervention phases of the BDRS2 study protocol

\section{Supplementary Files}

This is a list of supplementary files associated with this preprint. Click to download.

- StaRIchecklistBDRS2.docx 